\title{
What strategies do ulcerative colitis patients employ to facilitate adherence?
}

\author{
This article was published in the following Dove Press journal: \\ Patient Preference and Adherence \\ 27 January 2017 \\ Number of times this article has been viewed
}

\author{
Aki Kawakami ${ }^{1,2}$ \\ Makoto Tanaka ${ }^{3}$ \\ Makoto Naganuma ${ }^{4}$ \\ Shin Maeda ${ }^{5}$ \\ Reiko Kunisaki' \\ Noriko Yamamoto-Mitani ${ }^{2}$ \\ 'Inflammatory Bowel Disease Center, \\ Yokohama City University Medical \\ Center, Minami-ku, Yokohama, Japan; \\ ${ }^{2}$ Department of Gerontological Home \\ Care and Long-term Care Nursing, \\ Graduate School of Medicine, \\ University of Tokyo, Bunkyo-ku, Tokyo, \\ Japan; ${ }^{3}$ Ramathibodi School of Nursing, \\ Faculty of Medicine Ramathibodi \\ Hospital, Mahidol University, \\ Ratchathewi, Bangkok, Thailand; \\ ${ }^{4}$ Division of Gastroenterology \\ and Hepatology, Keio University, \\ Shinjuku-ku, Tokyo, Japan; \\ ${ }^{5}$ Department of Gastroenterology, \\ Yokohama City University Graduate \\ School of Medicine, Kanazawa-ku, \\ Yokohama, Japan
}

Background: Overall, $30 \%-45 \%$ of patients with ulcerative colitis (UC) are non-adherent and have difficulties taking their medications; this non-adherence increases the risk of clinical relapse 1.4- to 5.5-fold. This study aimed to clarify the strategies patients employ to facilitate adherence and determine whether the strategies had an impact on good adherence.

Methods: This was a cross-sectional survey using a self-administered questionnaire and review of medical records. Patients diagnosed as having UC and attending one of the outpatient clinics of four urban hospitals from June 2009 to December 2012 were enrolled. A questionnaire was developed to identify the strategies patients employ to facilitate adherence and then administered to patients with UC. Adherence to 5-aminosalicylic acid was calculated, and univariate and multiple logistic regression analyses were performed to determine the strategies that were associated with good adherence.

Results: The final analyses included 671 participants (mean age 40.2 years; $54.3 \%$ males). The valid response rate was $96.9 \% ; 186(27.7 \%)$ participants were classified as non-adherent, the mean adherence rate being $86.1 \%$ (standard deviation [SD] 17.9). Seven strategies that patients employ to facilitate adherence were identified, the following two being significantly associated with good adherence: "I keep my medicines where I eat meals" and "I keep each day's medicine in a pill case or something similar to make sure I have taken them".

Conclusion: The identified strategies might be used to develop a program to improve medication adherence in patients with UC.

Keywords: medication adherence, self-management, ulcerative colitis, 5-aminosalicylic acid

\section{Introduction}

The course of ulcerative colitis (UC), a chronic, idiopathic, inflammatory bowel disease (IBD) of the large intestine, is characterized by periods of relapse and remission. The causes of UC are unclear but are believed to be multifactorial, including a dysregulated immune system. ${ }^{1}$ Multiple studies have reported the efficacy of 5-aminosalicylic acid (5-ASA) as first-line therapy for inducing remission and preventing UC relapse., ${ }^{2,3}$ 5-ASA is therefore prescribed as maintenance therapy for most patients with UC. However, $30 \%-45 \%$ of patients are reportedly non-adherent to 5-ASA, non-adherence being defined as taking $<80 \%$ of the prescribed dose. ${ }^{4,5}$ Non-adherence increases the risk of clinical relapse 1.4- to 5.5-fold. ${ }^{4,6-8}$

Various factors related to non-adherence to medication have been reported, including forgetfulness, fear of side effects, lack of knowledge, and having too many pills. ${ }^{5,9-12}$ Some interventions to reduce these barriers and difficulties have been reported. ${ }^{13-17}$ Strategies such as regimen simplification or use of a reminder system are reportedly effective for enhancing medication adherence in patients with IBD; ${ }^{17}$ however, the results are inconsistent. ${ }^{18}$ Given that patients with UC are willing to make efforts to
Correspondence: Aki Kawakami Inflammatory Bowel Disease Center, Yokohama City University Medical Center, 4-57 Urafune-cho, Minami-ku, Yokohama 232-0024, Japan

Tel +8I 457872326

Fax +8I 457872327

Email akikawakami-tky@umin.ac.jp
Patient Preference and Adherence 2017:I I 157-163

157

Dovepress if in 0

http://dx.doi.org/1 0.2147/PPA.SI17841 (c) (1) (5) 2017 Kawakami et al. This work is published and licensed by Dove Medical Press Limited. The full terms of this license are available at https://www.dovepress.com/terms.php
and incorporate the Creative Commons Atribution - Non Commercial (unported, v3.0) License (http://creativecommons.org/licenses/by-nc/3.0/). By accessing the work you BY NC and incorporate the Creative Commons Attribution - Non Commercial (unported, v3.0) License (http:///creativecommons.org/licenses/by-nd $3.0 /$ ). By accessing the work you
hereby accept the Terms. Non-commercial uses of the work are permitted without any further permission from Dove Medical Press Limited, provided the work is properly attributed. For permission hereby accept the Terms. Non-commercial uses of the work are permitted without any further permission from Dove Medical Press Limited, provided the work is properly attributed. For permission
for commercial use of this work, please see parazraphs 42 and 5 of our Terms (https:/wwww.dovepress com/terms php). 
adopt some strategies for improving 5-ASA adherence, ${ }^{19-21}$ Ghosh $^{21}$ proposed that we need to further explore how to assist patients to acquire skills for improving medication adherence. Generally, such strategies should be easy to adopt and fit into patients' lifestyles without disrupting their daily lives. This study aimed to explore 1) the strategies patients with UC employ to facilitate adherence and 2) whether those strategies are in fact associated with good adherence.

\section{Methods}

\section{Study design and patients}

Patients diagnosed as having UC who were attending one of the outpatient clinics of four hospitals located in urban Japan from June 2009 to December 2012 were consecutively enrolled in this survey. The inclusion criteria were as follows: 1) met the criteria for $\mathrm{UC} ; 2$ ) aged $>20$ years; and 3) had been prescribed 5-ASA. Patients were excluded if they 1 ) had a history of surgery for $\mathrm{UC} ; 2$ ) were unable to complete the questionnaires; 3) had any serious complications; or 4) were participating in other clinical studies at the time of study entry.

This study was a cross-sectional survey using a selfadministered questionnaire and review of medical records. After the outpatient visit, the physician introduced the patient to one of the researchers. The researcher then explained the study protocol to each patient and obtained written, informed consent before handing him/her the questionnaire.

\section{Measures}

We hypothesized that there was a significant relationship between good adherence to 5-ASA and each adherence strategy, after adjusting for various factors (namely, psychosocial factors, disease characteristics, medication characteristics, abdominal symptoms, and sociodemographic characteristics).

\section{Strategies patients employ to facilitate adherence}

First, 12 patients with UC were asked the following question: "Please tell us what efforts or practices you engage to ensure you take 5-ASA as prescribed every day". Second, research experts in IBD (seven physicians, three clinical nurses, and two research nurses) were asked the following question: "Please tell us what efforts or practices you engage in to ensure that your patients take their prescribed drug(s) every day". Their answers were summarized into seven questionnaire items on how to maintain medication adherence. These items were further examined by 13 patients and eight IBD specialists for face validity, and all concluded that the items were relevant and representative of possible strategies patients employ to facilitate adherence. In the subsequent survey, these seven items were responded to on a 5-point Likert-scale ( $5=$ completely agree, $4=$ mostly agree, $3=$ unsure, $2=$ mostly disagree, and 1=completely disagree), with higher scores indicating more frequent use.

\section{Good adherence to 5-ASA}

A previously described method for calculating 5-ASA adherence $^{4,22}$ was used in this study. In short, the rate of adherence to 5-ASA during the 7 days prior to study enrollment was calculated by dividing reported taken dose by prescribed dose as written in the medical record according to a method used in previous studies..$^{23,24} \mathrm{We}$ did use pill count methods over $\sim 2$ months, a relatively long time in patients with UC taking 5-ASA, to investigate the validity of 7-day self-reports of adherence and found that most patients were within the accepted range of agreement. Good adherence to 5 -ASA was defined as taking $>80 \%$ of the prescribed doses and non-adherence as consumption of $\leq 80 \%{ }^{4,6}$

\section{Control variables: disease, medication, sociodemographic characteristics, abdominal symptoms, and psychological variables}

The following information was collected from the medical records or asked in the questionnaire: disease characteristics (age at diagnosis, duration of UC, family history, duration of current remission, disease region by recent colonoscopy), medication characteristics (type of 5-ASA, times of day drugs taken, daily number of tablets taken, daily prescribed dose, any current concomitant therapy for UC), and abdominal symptoms (stool consistency, bowel movements, urgency, pain, visible bleeding). Quantitative variables were categorized based on previous studies ${ }^{5}$ or using their median. Participants were asked about their sociodemographic characteristics (sex, age, employment status, marital status, educational level, and living situation) in the questionnaire. Patient-practitioner relationships were assessed as psychological variables. The doctor-patient relationship was assessed using the Japanese version of the trust in the physician scale..$^{25,26}$ The scale consists of 11 items; higher scores indicate greater trust. The validity and reliability of this scale have been confirmed.

\section{Statistical analysis}

Descriptive statistics are shown as mean and standard deviation (SD) for continuous variables and as $\mathrm{n}(\%)$ for categorical variables. First, univariate logistic regression analysis was performed to explore the strategies and control 
variables related to good adherence to 5-ASA. To facilitate interpretation of the relation between each strategy and good adherence, patients who responded with 5 or 4 to a questionnaire item on how to maintain medication adherence were designated the "usage" group, whereas those who responded with 1,2, or 3 were categorized as the "non-usage" group for that item. The control variables with significant associations with good adherence $(P<0.20)$ were entered into a multiple logistic regression model as independent variables for adjustment. When Pearson's correlation coefficient among the independent variables was $>0.7$, the variable with the smaller $P$-value was left in the model. A backward multiple logistic regression analysis was then conducted. Each strategy $(<0.20$ in univariate analysis) was assessed separately to determine whether it was significantly associated with good adherence after adjustment for control variables. Calibration of each final logistic model was assessed by the Hosmer-Lemeshow $\chi^{2}$ test. All analyses were performed with SAS version 9.4 for Windows (SAS Institute Inc., Cary, NC, USA).

\section{Ethical standards}

This study was approved by the ethics committee of each hospital from which participants were recruited The University of Tokyo, Yokohama City University Medical Center, Keio University and Social Insurance Central General Hospital. To maximize the chances of obtaining consent from patients with non-adherence and of accurate responses concerning their adherence, patients were informed before their consent to participate was requested that their responses to the questionnaire would be masked to their physicians.

\section{Results}

\section{Patients' characteristics}

The inclusion criteria were met by 709 patients, 18 of whom declined to participate and four of whom failed to return the questionnaire. The response rate was $96.9 \%$. Sixteen had missed items concerning strategies and were excluded from the analysis. Thus, 671 participants were included in the final analyses (Table 1). A total of 485 (72.3\%) participants were classified as having good adherence, the overall mean adherence rate being $86.1 \%$ (SD 17.9). The mean age was 40.2 years, and $54.3 \%$ were males. The mean prescribed 5-ASA dose was $3.3 \mathrm{~g} /$ day. One hundred and seventy-five of the participants $(26.1 \%)$ reported visible bleeding.

\section{Strategies patients employ to facilitate adherence}

Table 1 lists the median and interquartile range (IQR) of the strategies patients employ to facilitate adherence.
Table I Participants' characteristics $(n=67$ I)

\begin{tabular}{ll}
\hline Variables & $\mathrm{n}(\%)$, \\
& mean $\pm \mathrm{SD}$, or \\
& median with \\
& IQR \\
\hline
\end{tabular}

Strategies that patients employ to facilitate

adherence

I keep my drugs in a place where I can notice

them (Item I)

I keep my drugs in my bag or at the office or $\quad 4$

school in preparation for going out (Item 2)

I keep my medicines where I eat meals (Item 3)

I keep each day's meds in a pill case or

2

something similar to make sure I have taken

them (Item 4)

When going out, I take my drugs before leaving |

even if it is a little early (Item 5)

When I miss a dose, I make up for it to meet

the daily dose by taking extra at the next dose

(Item 6)

I have my family members or the people

around me remind me to take my drugs so

that I won't forget to take them (Item 7)

Psychological factors

Trust in the physician ${ }^{\mathrm{a}}$

$46.0 \pm 6.1$

Disease characteristics

Age at diagnosis, ${ }^{a}$ years

Duration of UC, years ${ }^{b}$

Family history ${ }^{c}$

Yes

No

4

(3-5)

4

The duration of current remission, months ${ }^{d}$

Disease region by recent colonoscopy ${ }^{\mathrm{e}}$

Total and left side

Rectum

I

I

Medication characteristics

5-ASA

Times a day drugs taken

$\leq 2$

$\geq 3$

224

447

Number of tablets/day

$7.8 \pm 2.1$

Any current concomitant therapy ${ }^{f}$

Yes

No

325

346

(48.4)

Abdominal symptoms

Stool consistency

Liquid

Formed

Bowel movements/day

$\geq 4$ times

$\leq 3$ times

Urgency

Yes

No

Pain $^{c}$

Yes

No

$31.3 \pm 11.9$

$8.9 \pm 6.9$

36

634

$22.0 \pm 28.7$

505

160

(75.9)

(33.4)

(66.6)

Visible bleeding

Yes

(26.I)

No 
Table I (Continued)

\begin{tabular}{|c|c|c|}
\hline Variables & \multicolumn{2}{|c|}{$\begin{array}{l}\text { n }(\%), \\
\text { mean } \pm S D \text {, or } \\
\text { median with } \\
\text { IQR }\end{array}$} \\
\hline \multicolumn{3}{|l|}{ Sociodemographic characteristics } \\
\hline \multicolumn{3}{|l|}{ Sex } \\
\hline Female & 307 & $(45.8)$ \\
\hline Male & 364 & $(54.2)$ \\
\hline Age, ${ }^{c}$ years & 40.2 & \\
\hline \multicolumn{3}{|l|}{ Employment $^{c}$} \\
\hline $\begin{array}{l}\text { Part time job, student, housewife, } \\
\text { unemployed }\end{array}$ & 281 & $(41.9)$ \\
\hline Full time job, family operated business & 389 & $(58.1)$ \\
\hline \multicolumn{3}{|l|}{ Marital status ${ }^{c}$} \\
\hline Unmarried, divorced, widowed & 282 & $(42.0)$ \\
\hline Married & 388 & $(58.0)$ \\
\hline \multicolumn{3}{|l|}{ Educational levelc ${ }^{c}$} \\
\hline College or higher & 351 & $(52.4)$ \\
\hline $\begin{array}{l}\text { Junior high school, high school, vocational } \\
\text { school, junior college }\end{array}$ & 319 & $(47.6)$ \\
\hline \multicolumn{3}{|l|}{ Living situation } \\
\hline Living alone & 114 & $(17.0)$ \\
\hline Living with someone & 557 & $(83.0)$ \\
\hline
\end{tabular}

Notes: ${ }^{a} n=668,{ }^{b} n=669,{ }^{c} n=670,{ }^{d} n=666$, and ${ }^{e} n=665$. Indicates the following therapies: topical therapy, corticosteroids, thiopurines, calcineurin inhibitors, leukocyte apheresis, and biologic agents.

Abbreviations: SD, standard deviation; IQR, interquartile range.

The strategies with high median scores were "I keep the medicines close to me" (Item 1), "I keep the medicines ready for going out" (Item 2), and "I keep the medicines where I eat meals" (Item 3). The strategies with low median scores were "When I go out, I take the drugs before leaving, even if that is a little early" (Item 5), "I take an extra dose at the next time when I have missed a dose" (Item 6), and "I have people remind me to take them" (Item 7).

\section{Relationships between the strategies patients employ to facilitate adherence and good adherence to 5-ASA}

Table 2 lists the results of univariate logistic regression analysis. Items 2 and 4 of the seven strategies were significantly associated with good adherence and Item 3 tended to be associated with it. The following factors were included in the multivariate logistic regression analyses as control variables: doctor-patient relationship, length of current remission, disease region by recent colonoscopy, daily number of tablets taken, any current concomitant therapy, and visible bleeding (Table 2). Because there was a significant association between current age and age at diagnosis ( $r s=0.86, P<0.01)$, we used age at diagnosis rather than current age. "I keep my medicines where I eat meals" (Item 2) and "I keep each day's meds in a
Table 2 Results of univariate logistic regression analysis of factors associated with good adherence $(n=67 I)$

\begin{tabular}{|c|c|c|c|}
\hline Variables & OR & $95 \% \mathrm{Cl}$ & $P$-value \\
\hline \multicolumn{4}{|c|}{ Strategies that patients employ to be adherent } \\
\hline \multicolumn{4}{|c|}{ I keep my drugs in a place where I } \\
\hline \multicolumn{4}{|l|}{ can notice them (Item I) } \\
\hline Usage & 0.99 & $0.68-1.43$ & 0.99 \\
\hline Non-usage & Reference & & \\
\hline \\
\hline \multicolumn{4}{|l|}{ the office or school in preparation } \\
\hline \multicolumn{4}{|l|}{ for going out (Item 2) } \\
\hline Usage & $\mid .31$ & $0.92-1.82$ & 0.13 \\
\hline Non-usage & Reference & & \\
\hline \multirow{2}{*}{\multicolumn{4}{|c|}{$\begin{array}{l}\text { I keep my medicines where I eat } \\
\text { meals (Item 3) }\end{array}$}} \\
\hline & & & \\
\hline Usage & 1.66 & $1.18-2.23$ & $<0.01$ \\
\hline Non-usage & Reference & & \\
\hline \multicolumn{4}{|l|}{ I keep each day's meds in a pill } \\
\hline \multicolumn{4}{|l|}{ case or something similar to make } \\
\hline \multicolumn{4}{|l|}{ sure I have taken them (Item 4) } \\
\hline Usage & 3.31 & $2.00-5.48$ & $<0.01$ \\
\hline Non-usage & Reference & & \\
\hline \multicolumn{4}{|l|}{ When going out, I take my drugs } \\
\hline \multicolumn{4}{|l|}{ before leaving even if it is a little } \\
\hline \multicolumn{4}{|l|}{ early (Item 5) } \\
\hline Usage & 0.77 & $0.50-1.17$ & 0.22 \\
\hline Non-usage & Reference & & \\
\hline \multicolumn{4}{|l|}{ When I miss a dose, I make up for } \\
\hline \multicolumn{4}{|l|}{ it to meet the daily dose by taking } \\
\hline \multicolumn{4}{|l|}{ extra at the next dose (Item 6) } \\
\hline Usage & 0.87 & $0.56-1.36$ & 0.55 \\
\hline Non-usage & Reference & & \\
\hline \multicolumn{4}{|l|}{ I have my family members or the } \\
\hline \multicolumn{4}{|l|}{ people around me remind me } \\
\hline to take my drugs so that I won' & & & \\
\hline forget to take them (Item 7) & & & \\
\hline Usage & 0.94 & $0.57-1.57$ & 0.83 \\
\hline Non-usage & Reference & & \\
\hline Psychological factors & & & \\
\hline Doctor-patient relationship ${ }^{a}$ & 1.04 & $1.008-1.06$ & 0.01 \\
\hline Disease characteristics & & & \\
\hline Age at diagnosis ${ }^{a}$ & 1.02 & $1.001-1.03$ & 0.03 \\
\hline Duration of $U C^{b}$ & 0.99 & $0.97-1.02$ & 0.75 \\
\hline Family history ${ }^{c}$ & & & \\
\hline Yes & 1.005 & $0.48-2.13$ & 0.99 \\
\hline No & Reference & & \\
\hline Duration of current remission ${ }^{d}$ & 0.99 & $0.98-0.99$ & 0.02 \\
\hline Disease region by recent & & & \\
\hline colonoscopy ${ }^{\mathrm{e}}$ & & & \\
\hline Total and left side & 1.53 & $1.04-2.24$ & 0.03 \\
\hline Rectum & Reference & & \\
\hline Medication characteristics & & & \\
\hline $5-A S A$ & & & \\
\hline Times of day drugs taken & & & \\
\hline$\leq 2$ & 1.15 & $0.87-|.5|$ & 0.33 \\
\hline$\geq 3$ & Reference & & \\
\hline Number of tablets/day & 1.09 & $1.001-1.19$ & 0.048 \\
\hline Any current concomitant thera & & & \\
\hline Yes & 1.78 & I.26-2.52 & $<0.01$ \\
\hline No & Reference & & \\
\hline
\end{tabular}

(Continued) 
Table 2 (Continued)

\begin{tabular}{|c|c|c|c|}
\hline Variables & OR & $95 \% \mathrm{Cl}$ & $P$-value \\
\hline \multicolumn{4}{|l|}{ Abdominal symptoms } \\
\hline \multicolumn{4}{|l|}{ Stool consistency } \\
\hline Liquid & 1.05 & $0.59-|.7|$ & 0.99 \\
\hline Formed & Reference & & \\
\hline \multicolumn{4}{|l|}{ Bowel movements/day } \\
\hline$\geq 4$ times & 1.20 & $0.85-1.68$ & 0.31 \\
\hline$\leq 3$ times & Reference & & \\
\hline \multicolumn{4}{|l|}{ Urgency } \\
\hline Yes & 1.24 & $0.88-1.76$ & 0.24 \\
\hline No & Reference & & \\
\hline \multicolumn{4}{|l|}{ Pain ${ }^{c}$} \\
\hline Yes & 0.95 & $0.65-1.39$ & 0.80 \\
\hline No & Reference & & \\
\hline \multicolumn{4}{|l|}{ Visible bleeding } \\
\hline Yes & 0.69 & $\mathrm{I} .00 \mathrm{I}-2.2 \mathrm{I}$ & 0.048 \\
\hline No & Reference & & \\
\hline \multicolumn{4}{|l|}{ Sociodemographic characteristics } \\
\hline \multicolumn{4}{|l|}{ Sex } \\
\hline Female & 1.003 & $0.7 I-1.4 I$ & 0.99 \\
\hline Male & Reference & & \\
\hline $\mathrm{Age}^{\mathrm{c}}$ & 1.01 & $0.99-1.03$ & 0.06 \\
\hline Employment $^{c}$ & Reference & & \\
\hline $\begin{array}{l}\text { Part time job, student, } \\
\text { housewife, unemployed }\end{array}$ & $\mathrm{I} .4 \mathrm{I}$ & $0.99-2.00$ & 0.05 \\
\hline $\begin{array}{l}\text { Full time job, family operated } \\
\text { business }\end{array}$ & Reference & & \\
\hline \multicolumn{4}{|l|}{ Marital status ${ }^{c}$} \\
\hline Unmarried, divorced, widowed & 1.19 & $0.85-1.68$ & 0.30 \\
\hline Married & Reference & & \\
\hline \multicolumn{4}{|l|}{ Educational level ${ }^{c}$} \\
\hline College or higher & 0.93 & $0.66-1.30$ & 0.66 \\
\hline $\begin{array}{l}\text { Junior high school, high school, } \\
\text { vocational school, junior college }\end{array}$ & Reference & & \\
\hline \multicolumn{4}{|l|}{ Living situation } \\
\hline Living alone & 1.19 & $0.77-1.85$ & 0.44 \\
\hline Living with someone & Reference & & \\
\hline
\end{tabular}

Notes: ${ }^{a} n=668,{ }^{b} n=669,{ }^{c} n=670,{ }^{d} n=666$, and ${ }^{e} n=665$. Indicates the following therapies: topical therapy, corticosteroids, thiopurines, calcineurin inhibitors, leukocyte apheresis, and biologic agents.

Abbreviations: $\mathrm{OR}$, odds ratio; $\mathrm{Cl}$, confidence interval.

pill case or something similar to make sure I have taken them" (Item 4) remained in each final logistic regression model after adjustment for other factors (Table 3). However, "I keep my drugs in my bag or at my office or school in case I need them while I am out of my house" (Item 2) was not significantly associated with good adherence (odds ratio $=1.34,95 \%$ confidence interval $=0.92-1.95, P=0.12$ ).

\section{Discussion}

The present study examined the strategies patients employ to facilitate adherence and their relationships with good adherence. The major findings of this study were as follows: 1) seven strategies that patients employ to facilitate adherence were
Table 3 Results of multivariate analysis of relationships between strategy items 2, 3, or 4 and good adherence $(n=657)$

\begin{tabular}{|c|c|c|}
\hline \multirow[t]{2}{*}{ Variables } & \multirow{2}{*}{$\frac{\text { Model I }}{\text { OR (95\% CI) }}$} & \multirow{2}{*}{$\frac{\text { Model } 2}{\text { OR }(95 \% \mathrm{CI})}$} \\
\hline & & \\
\hline \multirow{2}{*}{\multicolumn{3}{|c|}{$\begin{array}{l}\text { I keep my drugs in the place } \\
\text { where I take meals (Item 3) }\end{array}$}} \\
\hline & & \\
\hline Usage & $1.47(1.02-2.12)^{*}$ & \\
\hline Non-usage & Reference & \\
\hline \multirow{4}{*}{\multicolumn{3}{|c|}{$\begin{array}{l}\text { I keep each day's meds in a pill } \\
\text { case or something similar to } \\
\text { make sure I have taken them } \\
\text { (Item 4) }\end{array}$}} \\
\hline & & \\
\hline & & \\
\hline & & \\
\hline Usage & & $2.98(1.74-5.12)$ \\
\hline Non-usage & & Reference \\
\hline \multicolumn{3}{|l|}{ Disease region by recent } \\
\hline \multicolumn{3}{|l|}{ colonoscopy } \\
\hline Total and left side & $1.37(0.92-2.07)$ & $1.36(0.97-2.05)$ \\
\hline Rectum & Reference & Reference \\
\hline \multirow{2}{*}{\multicolumn{3}{|c|}{$\begin{array}{l}\text { Any current concomitant } \\
\text { therapy }\end{array}$}} \\
\hline & & \\
\hline Yes & $1.19(0.80-1.78)$ & $1.15(0.76-1.73)$ \\
\hline No & Reference & Reference \\
\hline Duration of current remission & $1.00(0.99-1.003)$ & $0.99(0.99-1.00)$ \\
\hline Age at diagnosis & $1.02(1.00-1.03)$ & $1.01(0.99-1.03)$ \\
\hline \multicolumn{3}{|l|}{ Visible bleeding } \\
\hline Yes & $1.46(0.94-2.25)$ & $1.39(0.89-2.16)$ \\
\hline No & Reference & Reference \\
\hline Doctor-patient relationship & $1.04(1.0 \mathrm{I}-1.07)^{*}$ & $1.03(1.002-1.06)^{*}$ \\
\hline Number of tablets/day & $1.04(0.95-1.14)$ & $1.02(0.93-1.13)$ \\
\hline Employment & $1.33(0.92-1.93)$ & $1.23(0.85-1.79)$ \\
\hline
\end{tabular}

identified and 2) two of these strategies were independently associated with good adherence after adjustment for control variables. No previous study has reported the strategies patients employ to facilitate adherence from the patients' perspective. These strategies may also be useful for patients with other chronic illness who take medications for a long time because we believe that such patients share certain characteristics with those with UC taking 5-ASA, for example, numerous pills and forgetfulness. Many patients reported keeping their medication where it readily attracted their attention during their daily activities (Items 1, 2, and 3). In this study, $\sim 70 \%$ of the patients took their medications more than three times a day, which meant that many of them had to take their medication in places other than their homes during the day. Therefore, study patients made a habit of keeping their medication in a bag or at their office or school. All participants employed some of the seven strategies in their daily lives. A previous study has shown that one of the important factors in facilitating self-care, including taking medication, is feasibility. ${ }^{27}$ The strategies identified in this study were therefore simple and 
easy and therefore would likely be helpful to other patients with UC who have not previously adopted them.

The items "I keep my medicines where I eat meals" and "I keep each day's meds in a pill case or something similar to make sure I have taken them" were independently associated with good adherence. Because patients are often instructed to take medications after meals, establishing an environment that enabled them to take drugs immediately after eating was thought to be related to good adherence. The use of a pill case, the efficacy of which has been reported by previous studies, ${ }^{16,28}$ was the strongest factor related to good adherence. This may be because this strategy helps patients to determine whether they have taken their medication. It is necessary in the future to identify factors associated with using a pill case and investigate ways of facilitating pill case use in daily life.

This study has some limitations, the first being selection bias: the study was conducted at IBD specialist clinics in urban areas and the participants may have been well educated regarding their disease and treatment. For example, the good adherence rate in this study was $\sim 70 \%$, which is slightly more than that in a previous review. ${ }^{5}$ Strategies and relationships between these strategies and good adherence should be investigated in different settings to confirm their generalizability. Second, adherence was only measured for short periods and assessed using a self-report questionnaire and medical records. Thus, our findings may be affected by the recall bias that is inherent to any retrospective study and may not reflect long-term adherence. Long-term adherence needs to be assessed using validated methods such as the Morisky Medication Adherence Scale- $8^{29}$ and measuring concentrations of metabolic products of 5-ASA in urine. Third, strategies for minimizing unintentional factors, for example forgetfulness, were mainly extracted in this study. However, it is important to assess intentional factors, such as understanding of the necessity of medication and concern about side effects, when distinguishing good adherence from non-adherence. Further studies need to elucidate intentional factors that relate to good adherence. Finally, because this was a cross-sectional study, it was not possible to evaluate whether employing the strategies would improve future medication adherence. Further prospective research is needed to evaluate strategies for improving adherence.

\section{Conclusion}

The strategies patients employ to facilitate adherence and their relationships with good adherence were evaluated. Some convenient strategies that patients employ to facilitate adherence were identified. Additionally, two of these strategies were independent predictors of good adherence after adjustment for control variables. Our findings may help in developing programs for improving medication adherence. Further prospective research is needed to evaluate strategies for promoting adherence.

\section{Acknowledgments}

The authors would like to thank all staff and patients who participated in this study. This study was supported by a Grantin-Aid for Young Scientists (B; 1979168) from the Ministry of Education, Culture, Sports, Science and Technology of Japan and by the Chiyoda-Kenko Foundation, Japan.

\section{Author contributions}

All authors contributed toward data analysis, drafting and critically revising the paper and agree to be accountable for all aspects of the work.

\section{Disclosure}

The authors report no conflicts of interest in this work.

\section{References}

1. Baumgart DC, Carding SR. Inflammatory bowel disease: cause and immunobiology. Lancet. 2007;369(9573):1627-1640.

2. Dignass A, Lindsay JO, Sturm A, et al. Second European evidencebased consensus on the diagnosis and management of ulcerative colitis part 2: current management. J Crohns Colitis. 2012;6(10):991-1030.

3. Ford AC, Achkar JP, Khan KJ, et al. Efficacy of 5-aminosalicylates in ulcerative colitis: systematic review and meta-analysis. Am J Gastroenterol. 2011;106(4):601-616.

4. Kawakami A, Tanaka M, Nishigaki M, et al. Relationship between nonadherence to aminosalicylate medication and the risk of clinical relapse among Japanese patients with ulcerative colitis in clinical remission: a prospective cohort study. J Gastroenterol. 2013;48(9):1006-1015.

5. Jackson C, Clatworthy J, Robinson A, Horne R. Factors associated with non-adherence to oral medication for inflammatory bowel disease: a systematic review. Am J Gastroenterol. 2009;105(3):525-539.

6. Kane S, Huo D, Aikens J, Hanauer S. Medication nonadherence and the outcomes of patients with quiescent ulcerative colitis. Am J Med. 2003; 114(1):39-43.

7. Khan N, Abbas AM, Bazzano LA, Koleva YN, Krousel-Wood M. Longterm oral mesalazine adherence and the risk of disease flare in ulcerative colitis: nationwide 10-year retrospective cohort from the veterans affairs healthcare system. Aliment Pharmacol Ther. 2012;36(8):755-764.

8. Robinson A, Hankins M, Wiseman G, Jones M. Maintaining stable symptom control in inflammatory bowel disease: a retrospective analysis of adherence, medication switches and the risk of relapse. Aliment Pharmacol Ther. 2013;38(5):531-538.

9. Kawakami A, Tanaka M, Ochiai R, et al. Difficulties in taking aminosalicylates for patients with ulcerative colitis. Gastroenterol Nurs. 2012;35(1):24-31.

10. Bernick SJ, Kane S. Insight into the widespread problem of nonadherence to therapy in ulcerative colitis patients. Expert Rev Clin Immunol. 2010;6(4):677-682.

11. DiMatteo MR. Variations in patients' adherence to medical recommendations: a quantitative review of 50 years of research. Med Care. 2004;42(3):200-209.

12. Osterberg L, Blaschke T. Adherence to medication. NEngl J Med. 2005; 353(5):487-497.

13. Waters BM, Jensen L, Fedorak RN, Waters BM, Jensen L, Fedorak RN. Effects of formal education for patients with inflammatory bowel disease: a randomized controlled trial. Can J Gastroenterol. 2005;19(4): 235-244. 
14. Elkjaer M, Shuhaibar M, Burisch J, et al. E-health empowers patients with ulcerative colitis: a randomised controlled trial of the web-guided 'Constant-care' approach. Gut. 2010;59(12):1652-1661.

15. Moss AC, Chaudhary N, Tukey M, et al. Impact of a patient-support program on mesalamine adherence in patients with ulcerative colitis-a prospective study. J Crohns Colitis. 2010;4(2):171-175.

16. Moshkovska T, Stone MA, Smith RM, Bankart J, Baker R, Mayberry JF. Impact of a tailored patient preference intervention in adherence to 5-aminosalicylic acid medication in ulcerative colitis: results from an exploratory randomized controlled trial. Inflamm Bowel Dis. 2011;17(9): 1874-1881.

17. Greenley RN, Kunz JH, Walter J, Hommel KA. Practical strategies for enhancing adherence to treatment regimen in inflammatory bowel disease. Inflamm Bowel Dis. 2013;19(7):1534-1545.

18. Kane S, Huo D, Magnanti K. A pilot feasibility study of once daily versus conventional dosing mesalamine for maintenance of ulcerative colitis. Clin Gastroenterol Hepatol. 2003;1(3):170-173.

19. Bosworth HB, Oddone EZ, Weinberger M. Patient Treatment Adherence. New York: Taylor and Francis Group; 2006.

20. O’Donohue WT, Levensky ER. Promoting Treatment Adherence. California: SAGE Publications; 2006.

21. Ghosh S. The challenges of medication non-adherence in ulcerative colitis: practical suggestions to help patients. J Crohns Colitis. 2008; 2(1):97-98.

22. Kawakami A, Tanaka M, Nishigaki M, et al. A screening instrument to identify ulcerative colitis patients with the high possibility of current non-adherence to aminosalicylate medication based on the Health Belief Model: a cross-sectional study. BMC Gastroenterol. 2014;19(14):200.
23. Simoni JM, Kurth AE, Pearson CR, Pantalone DW, Merrill JO, Frick PA. Self-report measures of antiretroviral therapy adherence: a review with recommendations for HIV research and clinical management. AIDS Behav. 2006;10(3):227-245.

24. Stirratt MJ, Dunbar-Jacob J, Crane HM, et al. Self-report measures of medication adherence behavior: recommendations on optimal use. Transl Behav Med. 2015;5(4):470-482.

25. Yamamoto T, Hashimoto M. Nihongoban Trust in Physician Scale no sakusei oyobi sinraisei datousei no kensyou [reliability and validity of a Japanese version of the trust in physician scale]. Nihoniryou Byoin Kanrigaxtukaisi. 2008;45(3):227-235. Japanese.

26. Anderson LA, Dedrick RF. Development of the trust in physician scale: a measure to assess interpersonal trust in patient-physician relationships. Psychol Rep. 1990;67(3 pt 2):1091-1100.

27. Foster G, Taylor SJC, Eldridge SE, Ramsay J, Griffiths CJ. Selfmanagement education programmes by lay leaders for people with chronic conditions. Cochrane Database Syst Rev. 2008;4:CD005108.

28. Haynes BR, Ackloo E, Sahota N, McDonald PH, Yao X. Interventions for enhancing medication adherence. Cochrane Database Syst Rev. 2008; (2):CD000011.

29. Trindade AJ, Ehrlich A, Kornbluth A, Ullman TA. Are your patients taking their medicine? Validation of a new adherence scale in patients with inflammatory bowel disease and comparison with physician perception of adherence. Inflamm Bowel Dis. 2011;17(2):599-604.
Patient Preference and Adherence

\section{Publish your work in this journal}

Patient Preference and Adherence is an international, peer-reviewed, open access journal that focuses on the growing importance of patient preference and adherence throughout the therapeutic continuum. Patient satisfaction, acceptability, quality of life, compliance, persistence and their role in developing new therapeutic modalities and compounds to optimize

\section{Dovepress}

clinical outcomes for existing disease states are major areas of interest for the journal. This journal has been accepted for indexing on PubMed Central. The manuscript management system is completely online and includes a very quick and fair peer-review system, which is all easy to use. Visit http://www. dovepress.com/testimonials.php to read real quotes from published authors. 